\title{
Familial primary hypomagnesemia with hypercalciuria and nephrocalcinosis
}

INSERM

\section{Source}

INSERM. (1999). Orphanet: an online rare disease and orphan drug data base. Familial primary hypomagnesemia with hypercalciuria and nephrocalcinosis. ORPHA:306516

Familial primary hypomagnesemia with hypercalciuria and nephrocalcinosis (FHHNC) is a form of familial primary hypomagnesemia (FPH, see this term), characterized by renal magnesium (Mg) and calcium (Ca) wasting, nephrocalcinosis, kidney failure and, in some cases, severe ocular impairment. Two subtypes of FHHNC are described: FHHNC with severe ocular involvement ( $\mathrm{FHHNCOI}$ ) and without severe ocular involvement ( $\mathrm{FHHN}$ ) (see these terms). 